\title{
Study on novel fluorescent carbon nanomaterials in food analysis
}

\author{
Ngafwan NGAFWAN $^{1 \star}$ (D), Harun RASYID ${ }^{2 \star}$, Emad SALAAM ABOOD ${ }^{3}$, Walid KAMAL ABDELBASSET ${ }^{4,5}$, \\ Sarmad Ghazi Al-SHAWI ${ }^{6}$, Dmitry BOKOV ${ }^{7,8}$, Abduladheem Turki JALIL ${ }^{9,10}$
}

\begin{abstract}
One of the most significant nanobiotechnology and nanomaterial science areas today is the production of novel sensors and biosensors with applications in the food industry. Carbon quantum dots (CQDs) are a new generation of carbon nanoparticles with a lot of potential for food analysis. CQDs with robust physicochemical properties are one of the most recently researched carbon nanomaterials. This material has outstanding optical properties such as light persistence, photobleaching tolerance, photoluminescence, and the advantages of fast functionalization and strong biocompatibility, rendering it an excellent raw material for sensing devices. Thanks to its considerable features such as fast result outputs, low expense, ease of service, and high sensitivity, fluorescence analysis has tremendous potential for food protection. The aim of this article is to familiarise yourself with carbon points, their synthesis methods, and their optical properties. Finally, fluorescence sensors can be used to detect food additives, heavy metals, bacteria, insecticide residues, antibiotics, and nutritional components in food samples. CQDs' problems and opportunities in the area of food safety were also addressed.
\end{abstract}

Keywords: food industry; carbon quantum dots; optical properties; fluorescence.

Practical Application: We aimed to study and review the novel fluorescent carbon nanomaterials in food analysis. Fluorescence sensors can be used to detect food additives, heavy metals, bacteria, insecticide residues, antibiotics, and nutritional components in food samples. Carbon quantum dots' problems and opportunities in the area of food safety were also addressed.

\section{Introduction}

Nanotechnology and the use of engineered nanomaterials and nanoparticles have enormous potential for improving food quality, primarily through the development of new applications such as the development of systems for transporting and absorbing food and bioactive materials, the improvement of colors and flavors, the functionalization of compounds, and tracking (Shetta et al., 2019). Microbial compounds, allergens, contaminants, and food packaging processes are all under control. Nanotechnology, like many other sciences, has carved out a niche in the packaging industry. The use of nanocomposites to create the desired changes in packaging films is the most common application of this technology. Physical properties (inhibit gas exchange), biochemical properties (environmental compatibility and degradability), and functional properties (antimicrobial properties, UV absorption, odor, and antioxidants, as well as antioxidants and antioxidants) are all improved by these compounds. Also, the development of intelligent sensors to detect food spoilage.

Nanomaterials have also opened up new possibilities for improving foods' health-promoting properties and the transfer of bioactive compounds in food. One of the practical achievements of using this technology and nanomaterials in the food and food industry is sustainability. Nano-encapsulated nutrients or chemicals, antimicrobial nanoparticles, and intelligent and active food packaging will be among the most common applications (Amenta et al., 2015).

Chemical, biological, and food contamination can occur as a result of the development of modern agriculture and the food processing industry. Food analysis is necessary for both quality control and food safety (Zhao et al., 2018; Khazimov et al., 2021). Spectroscopy, risk assessment, culture and colony counting, chromatography, nuclear magnetic resonance, and electrochemical methods are common analysis methods. These methods have the advantages of reproducibility, sensitivity, and high selectivity. These techniques necessitate costly equipment, highly trained personnel, and long separations (Wang et al., 2019c). Fluorescence analysis has several advantages over traditional analysis methods, including simplicity, high sensitivity, low cost, and simple equipment. For fluorescence analysis, organic fluorescent dyes and quantum

Received 01 June, 2021

Accepted 08 June, 2021

${ }^{1}$ Department of Mechanical Engineering, Faculty of Engineering, Universitas Muhammadiyah Surakarta, Jawa Tengah, Indonesia

${ }^{2}$ Agroteknologi, Fakultas Pertanian Peternakan, Universitas Muhammadiyah Malang, Malang, Indonesia

${ }^{3}$ Medical physics department, Hilla university college, Babylon, Iraq

${ }^{4}$ Department of Health and Rehabilitation Sciences, College of Applied Medical Sciences, Prince Sattam bin Abdulaziz University, Al Kharj, Saudi Arabia

${ }^{5}$ Department of Physical Therapy, Kasr Al-Aini Hospital, Cairo University, Giza, Egypt

${ }^{6}$ Food Science Department-Agriculture College-Basrah University, Basrah, Iraq

${ }^{7}$ Institute of Pharmacy, Sechenov First Moscow State Medical University, Moscow, Russian Federation

${ }^{8}$ Laboratory of Food Chemistry, Federal Research Center of Nutrition, Biotechnology and Food Safety, Moscow, Russian Federation

${ }^{9}$ Faculty of Biology and Ecology, Yanka Kupala State University of Grodno, Grodno, Belarus

${ }^{10}$ College of Medical Technology, The Islamic University, Najaf, Iraq

*Corresponding authors: ngafwan@ums.ac.id; harun@umm.ac.id 
dots are commonly used, but their use in the food industry is limited due to their drawbacks. Organic fluorescent paints are easily optically decolorized, and semiconductor quantum dots contain highly toxic heavy metals (Shi et al., 2019; Wang et al., 2019b; Astafyev \& Ivanchenko, 2021).

Quantum dots are nanoparticles with size-dependent electron and optical properties used in various applications, including energy-efficient displays, photovoltaics, and biomarkers. Quantum dots have a number of advantages over other fluorescence compounds, including bright fluorescence, high optical stability, and resistance to metabolic degradation in biological applications (Pandey et al., 2020). Due to the presence of toxic metal elements such as cadmium, these quantum dots have limited applications. Many efforts have been made to develop non-toxic or low-toxic compounds. As a result, they developed carbon-based quantum dots, which consist of carbon nanoparticles smaller than $11 \mathrm{~nm}$ (quantum dot carbon) and graphene nanoparticles smaller than $111 \mathrm{~nm}$ (quantum dot graphene) (quantum dot graphene). Because of their high biocompatibility, low toxicity, excellent optical properties, and chemical inertia, these compounds have gotten a lot of attention (Lu et al., 2018; Pacquiao et al., 2018; Pan et al., 2019; Kipriyanov et al., 2021).

CQDs (Carbon quantum dots) were a type of zero-dimensional nanomaterial also known as CDs (carbon dots) first discovered in 2004 with a size of less than $10 \mathrm{~nm}$. Since their discovery, scientists have been fascinated by carbon-based nanomaterials. Carbon-containing nanomaterials are classified as graphene coil (multidimensional), graphene (two-dimensional), carbon nanotubes (one-dimensional), fullerenes (zero-dimensional), and so on, based on their spatial dimensions (Cao et al., 2021; $\mathrm{Li}$ et al., 2018). The properties of carbon nanomaterials were described in Table 1 in a number of ways.

The Scanning electron microscope (SEM) image of the Mesoporous Hematite composite - carbon quantum dots is shown in Figure 1.

CQDs, which are a form of environmentally friendly carbon nanomaterial, have robust physicochemical properties, strong biocompatibility, and the potential to diffuse in water. They're easy to put together and use (Wang et al., 2018; Yadav et al., 2018). Fluorescent CQDs have a number of promises for safe lightning, thin film screens, biomedicine, optoelectronic systems, photocatalysis, and other areas. CQDs have interesting and significant features such as greater quantum size impact, low toxicity, specific biological objective, and good biocompatibility when compared to conventional semiconductor-based quantum dots, which can be achieved through low-cost fabrication techniques, and have drawn a lot of interest from researchers. CQDs are known as graphene quantum dots (GQDs), carbon nanodots (CNDs), and polymer dots, depending on the carbon cores they hold (PDs). CQDs are all very small particles with

Table 1. The most common carbon-based nanomaterials

\begin{tabular}{|c|c|c|c|}
\hline Category & Diameter & Dimension & Parameters \\
\hline \multirow[t]{3}{*}{ Carbon nanotubes } & \multirow[t]{3}{*}{$0.5-99 \mathrm{~nm}$} & \multirow[t]{3}{*}{ one } & Thermal conductivity: $3500 \mathrm{~W} \mathrm{~m}^{-1} \mathrm{~K}^{-1}$ \\
\hline & & & (SWCNT); \\
\hline & & & Young's modulus: $1 \mathrm{TPa}$ \\
\hline \multirow[t]{2}{*}{ Ordered mesoporous carbon } & \multirow[t]{2}{*}{$3-45 \mathrm{~nm}$} & \multirow[t]{2}{*}{-} & Pore volume: $1.5 \mathrm{~cm}^{3} \mathrm{~g}^{-1}$ \\
\hline & & & Specific surface area: $500-2500 \mathrm{~m}^{2} \mathrm{~g}^{-1}$; \\
\hline \multirow{7}{*}{ Graphene } & \multirow{7}{*}{-} & \multirow[t]{7}{*}{ two } & Resistivity: $10^{-6} \Omega \cdot \mathrm{cm}$ \\
\hline & & & Young's modulus: $1 \mathrm{TPa}$ \\
\hline & & & Thermal conductivity: $5300 \mathrm{~W} \mathrm{~m}^{-1} \mathrm{~K}^{-1}$ \\
\hline & & & (Single layer); \\
\hline & & & Carrier mobility: $15,000 \mathrm{~cm}^{2} \mathrm{v}^{-1} \mathrm{~s}^{-1}$; \\
\hline & & & Specific capacitance: $100-230 \mathrm{~F} \mathrm{~g}^{-1}$; \\
\hline & & & Specific surface area: $2630 \mathrm{~m}^{2} \mathrm{~g}^{-1}$ \\
\hline Carbon dots & $<9 \mathrm{~nm}$ & zero & - \\
\hline
\end{tabular}
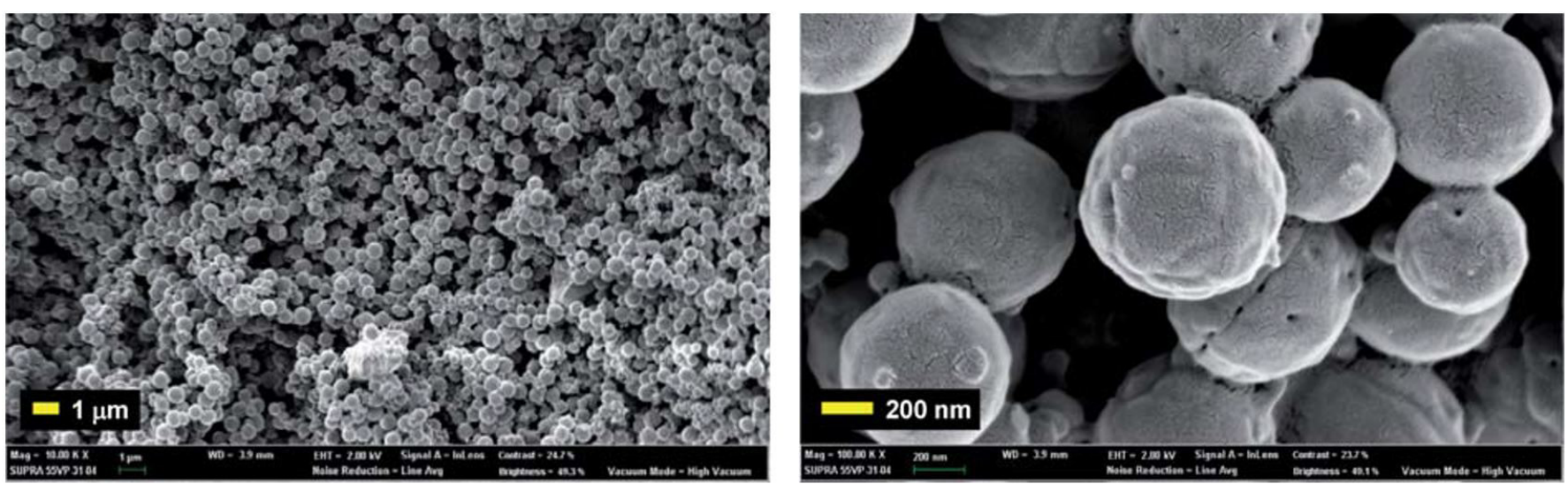

Figure 1. Carbon quantum dots - SEM image of mesoporous hematite composite. 
a wide basic surface region, regardless of the form they are (Parra et al., 2020; Verma et al., 2020). Various studies on the synthesis and use of carbon quantum dots have been conducted in recent years. However, there is very little research on the use of these new and practical compounds in food, particularly food packaging. Because some of carbon quantum dots' intrinsic properties, such as antimicrobial properties, can aid active packaging researchers in developing packaging films with unique properties (Schneider et al., 2019; Surendran et al., 2021).

Electrophoresis during the purification of single-walled carbon nanotubes led to the discovery of quantum carbon dots. Carbon quantum dots are a new type of zero-dimensional carbon nanomaterial with a spherical shape and a diameter of fewer than 10 nanometres (Robby et al., 2021). Their main advantage over organic dyes, as with other common semiconductor quantum dots, is their high optical stability. Carbon quantum dots, unlike other quantum dots, are usually low in toxicity and biocompatible (Hu et al., 2020; Luo et al., 2018; Rawtani et al., 2019). The carbon atoms $\mathrm{sp}^{2}$ and $\mathrm{sp}^{3}$ are located as nuclei in an amorphous shell made up of functional groups in terms of chemical structure. The presence of many hydroxyl and carboxyl functional groups on the surface of carbon spots, as shown in Figure 2, results in good water solubility and ease of functionalization by various species. Depending on the synthesis method, the amount of oxygen in carbon quantum dots ranges from 5 to $50 \%$ by weight. Small carbon nanoparticles in solution or other suspensions are referred to as carbon dots. Quant dots were the name given to these fluorescent carbon nanoparticles. In 2006, a synthetic method for producing quantum dots carbon with a higher fluorescence emission through the transition surface was introduced (Figure 2) (Wang et al., 2019a).

The aim of this article is to introduce you to carbon points, as well as their synthesis methods and optical properties. Food additives, heavy metals, bacteria, insecticide residues, antibiotics, and nutritional ingredients can all be detected using fluorescence sensors.

\section{Material and methods}

\subsection{The attributes of CQDs' fluorescence and their detection mechanisms}

CQDs have a range of optical characteristics, including photoluminescence. The molecular and molecule-like states, surface defect states, quantum size effect, and others have all

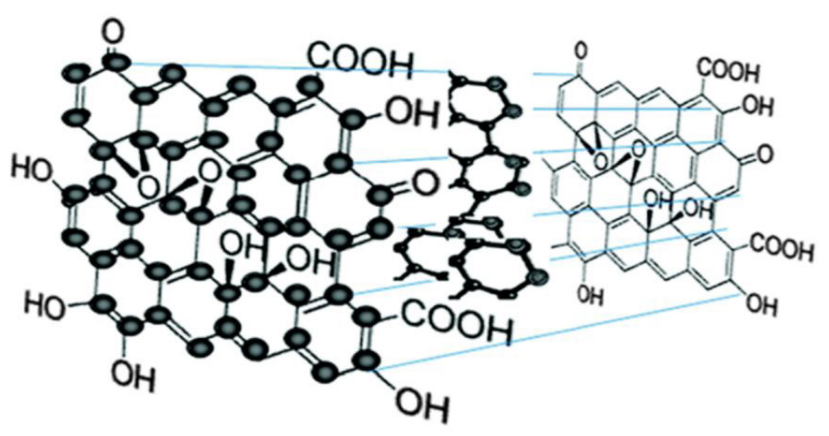

Figure 2. Chemical structure of carbon quantum dots. been identified as luminescence mechanisms (Liu et al., 2019). Nevertheless, there was a broad raw material supply and a number of preparation methods for synthesizing CQDs, which included complicated materials and structures. Since it's challenging to come up with a single explanation by combining findings from previous studies, the photoluminescence process of CQDs needs to be investigated further. CQDs have strong fluorescence stability, which ensures that even under long-term continuous vibrations, the fluorescence emission strength will stay constant (Guo et al., 2015; Liang et al., 2016). CQDs also have excellent biocompatibility and low toxicity. CQD-based fluorescent sensors for food analysis have gotten a lot of coverage as a result of this.

\subsection{Internal filter effect}

In fluorescence spectroscopy, the inner filter effect is a general issue that affects spectral measurements in particular (N. Zhao et al., 2020). Only the surface approaching the excitation beam fluoresces intensely in extremely focused fluids since the excitation beam is attenuated by the sample. The lower fluorescence emission in the middle of the cuvette, which is imaged by the fluorescence spectrometer's emission monochromator, influences the signal observed (Q. Zhang et al., 2020). The main inner filter effect applies to the attenuation of the excitation beam mentioned above. Furthermore, if the excitation and emission spectra are slightly overlapping, the light released in the center will be reabsorbed by the sample. The secondary inner filter influence is what this is referred to as (Bi et al., 2021; Yue et al., 2020). Users must learn to understand and stop the inner filter effect, which induces spectral distortion and, in certain situations, total signal loss. Measuring fluorescence spectra at various sample concentrations is a smart idea: if fluorescence varies linearly with concentration, this influence isn't present.

\subsection{Photoinduced electron transfer}

Due to their adjustable optical properties, quantum dots played a key role in the revolution of photovoltaic devices (Yuan et al., 2009; Zhang et al., 2018). Due to their large surface area, adjustable energy gap, and high electron exchange, graphene quantum dots are highly efficient compounds for photovoltaic devices. Also, due to their excellent electron-electron properties, low cost, high luminescence properties, and ability to perform processes, colloidal graphene dot colloids are widely used in solar cells as electron acceptors in the soluble phase (Cui et al., 2011; Miao et al., 2014; Yang et al., 2020).

\section{Results and discussion}

\subsection{Metal ion detection}

Some popular metal ions, including copper $\left(\mathrm{Cu}^{2+}\right)$, mercury $\left(\mathrm{Hg}^{2+}\right)$, and aluminum $\left(\mathrm{Al}^{3+}\right)$, are toxic, non-biodegradable, and their presence in food chain may result in a variety of health issues (Figure 3). As a result, their identification is a critical aspect of safety surveillance of food.

Heavy metal ions such as $\mathrm{Hg}^{2+}, \mathrm{Au}^{3+}, \mathrm{Cr}^{6+}, \mathrm{Ag}^{+}, \mathrm{Fe}^{2+}, \mathrm{Cu}^{2+}$, and $\mathrm{Fe}^{3+}$, which are easily accumulated in animals and plants, are a significant factor that contributes to water or environmental 


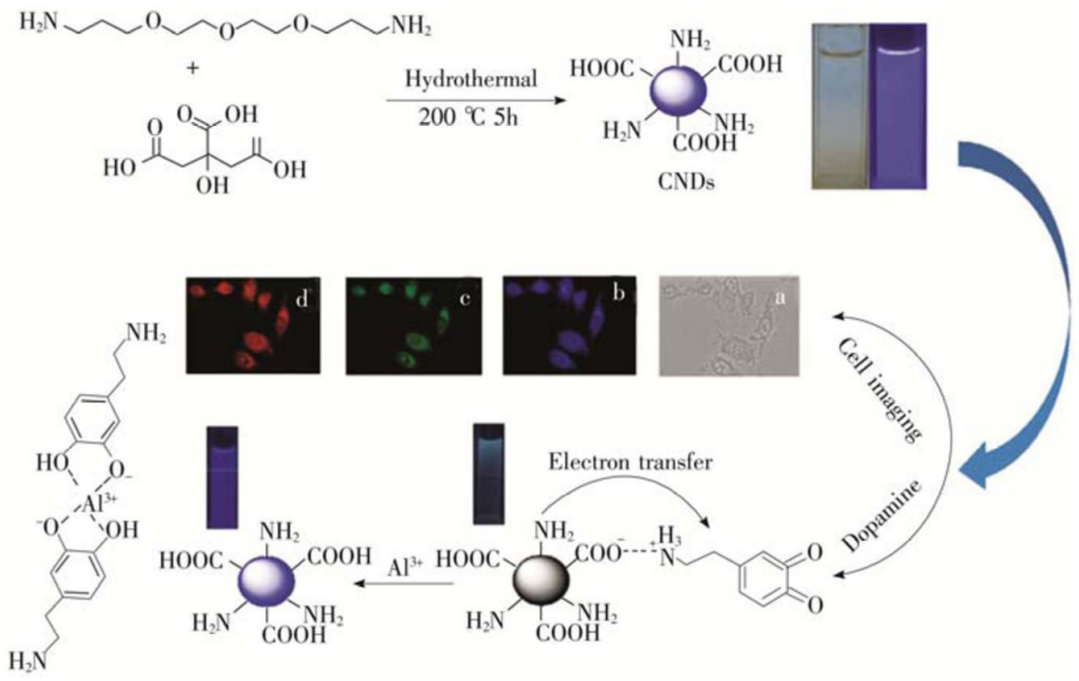

Figure 3. Carbon dots are synthesized and used as a fluorescent probe for $\mathrm{Al}^{3+}$.

degradation. They will accumulate toxicity in the human body after accessing it via the food chain. The creation of a system for detecting heavy metal ions in foods that is accurate, simple, and sensitive is crucial.

\subsection{Foodborne pathogen detection}

Food poisoning has been a global problem. Food pathogen identification may be affected by new regulations on food and health. Phage-based biosensors have recently gained a lot of publicity as a form of the modern biosensor. Bacteriophages (phages) are obligate intracellular parasitic bacteria that reproduce by using any or all of the host's biosynthetic machinery. Phage longevity and selectivity are important characteristics for their eventual usage as biosensing components. Phages are less delicate and resilient to environmental stress, such as $\mathrm{pH}$ and temperature fluctuations than antibodies, allowing them to track pathogens, microbes, and spores over longer periods of time in the field. Via their tail spike proteins, phages recognize bacterial receptors. Since the identification is so specific, it can be used to type bacteria, opening the way for the creation of increasingly specific pathogen detection technologies. Bioluminescence, Amperometric, acoustic, quartz crystal microbalance, and surface plasmon resonance (SPR) biosensors may have complex tracking phage probes directly attached to the sensor surface.

\subsection{Food additives detection}

Additives are widely used in food processing to improve taste, shelf life, and nutritional value. Additives have long been misused, and they are one of the leading causes of foodborne illness. As a consequence, it's important to establish a quick and effective food additive detection system in order to enhance food additive tracking. To improve the monitoring of food additives, a quick and reliable diagnostic method must be developed. Scientists used aloe vera to make carbon quantum dots, which were covered by a static mechanism in the presence of tartrazine fluorescence. With a detection range of $73 \mathrm{nM}$, this sensor was used to detect low levels of tartrazine in honey and candy.

\subsection{Veterinary drug and pesticide residues}

Pesticide and veterinary medication residues in crops, as well as drug prototypes and their metabolites that accumulate in foods, pose a risk to human health. One of the most relevant issues of food protection science is the successful study of these residues. The newly developed CQDs content has the potential to provide more precise, reliable, and cost-effective fluorescent sensing, which has enabled significant advances in recent years in the identification of pesticide and veterinary drug residues in food. Insecticides are widely used in agriculture to control weeds, pests and increase crop yields. Excessive insecticide use can contaminate the non-target environment, which can lead to food contamination. Neurotoxicity, endocrine disorders, mutagenicity, and carcinogenesis are some of the negative effects of insecticides on humans. As a result, a sensitive and selective method for analyzing these compounds is required. Carbon points have been used in recent studies to detect insecticides with low detection ranges, such as parathion methyl, dimethoate, dichlorvos, and carbaryl.

\subsection{Nutritional components detection}

Using fluorescence sensors to detect nutritional compounds such as ascorbic acid in fruits and retinoic acid, B vitamins, and vegetables has been the subject of numerous studies. Covering the fluorescence of carbon points with metal ions and then recovering the fluorescence with the analyte is a common mechanism for detecting nutrient components. In other words, electron transfer and fluorescence coating are caused by electrostatic interactions between metal ions and the surface groups of carbon points. The addition of the analyte restores fluorescence due to the chelation of the analyte and metal ions. Glutathione and thiamine have been detected in food using this mechanism.

The fluorescence quenching of CDs was caused by the electrostatic contact of metal ions with CDs on the surface, as well as electron transfer. Due to the intense chelating influence between the analyte and metal ion, the fluorescence of the CDs steadily returned after introducing the analyte, enabling quantitative 
examination of the analyte to be accomplished. Animals, animals, and microorganisms all possess glutathione (GSH), which serves as a redox buffer to preserve cellular redox control.

\section{Conclusion}

In conclusion, CQD-based fluorescence analysis in the area of food analysis has a wide range of applications. However, certain questions do need to be resolved before food analysis can be utilized in the real world. For e.g., most existing CQDbased detection methods can only detect one analyte per test; however, developing CQD-based fluorescent sensors that can detect several analytes at the same time is the future trend. Furthermore, most CQD-based fluorescent sensors use the fluorescence strength of a single probe as the reaction signal, which may be affected by an instrument error, solvent, and other experimental influences. By self-calibrating two types of fluorescence strength, the ratiometric fluorescent sensor can eliminate the above interference and achieve higher analysis precision than a single-signal fluorescent sensor.

Also, ratiometric fluorescence approaches may be used for fast identification and detection of color variations, which are often present. The visual and compact multi-component identification would be the goal of CQDs in food detection in the future. Carbon-based sensors, without a doubt, have bright prospects for food analysis. Carbon point research, on the other hand, is still in its infancy. The principles of the photoluminescence mechanism, for example, are still unknown, and more research is required. Most synthesis methods produce carbon points with poor quantum performance, so various efforts have been made to improve quantum performance, such as doping and changing the reaction environment. Identifying a specific target without the involvement of other sample components is difficult because food samples contain a variety of biological and chemical components. This emphasizes the significance of using connectors that can detect a specific target.

\section{References}

Amenta, V., Aschberger, K., Arena, M., Bouwmeester, H., Botelho Moniz, F., Brandhoff, P., Gottardo, S., Marvin, H. J., Mech, A., Quiros Pesudo, L., Rauscher, H., Schoonjans, R., Vettori, M. V., Weigel, S., \& Peters, R. J. (2015). Regulatory aspects of nanotechnology in the agri/feed/ food sector in EU and non-EU countries. Regulatory Toxicology and Pharmacology, 73(1), 463-476. http://dx.doi.org/10.1016/j. yrtph.2015.06.016. PMid:26169479.

Astafyev, V. L., \& Ivanchenko, P. G. (2021). Assessment of methods of the autumn-winter moisture accumulation in poor draining soil in the arid region of Northern Kazakhstan. Journal of Water and Land Development. http://dx.doi.org/10.24425/jwld.2021.136154.

Bi, X., Li, L., Liu, X., Luo, L., Cheng, Z., Sun, J., Cai, Z., Liu, J., \& You, T. (2021). Inner filter effect-modulated ratiometric fluorescence aptasensor based on competition strategy for zearalenone detection in cereal crops: Using mitoxantrone as quencher of CdTe QDs@ SiO2. Food Chemistry, 349, 129171. http://dx.doi.org/10.1016/j. foodchem.2021.129171. PMid:33582542.

Cao, L., Li, J., Song, Y., Cong, S., Wang, H., \& Tan, M. (2021). Molecular interaction of fluorescent carbon dots from mature vinegar with human hemoglobin: Insights from spectroscopy, thermodynamics and AFM. International Journal of Biological Macromolecules,
167, 415-422. http://dx.doi.org/10.1016/j.ijbiomac.2020.11.203. PMid:33278433.

Cui, S.-C., Tachikawa, T., Fujitsuka, M., \& Majima, T. (2011). Photoinduced Electron Transfer in a Quantum Dot- Cucurbituril Supramolecular Complex. The Journal of Physical Chemistry C, 115(5), 1824-1830. http://dx.doi.org/10.1021/jp1110828.

Guo, Y., Zhang, L., Zhang, S., Yang, Y., Chen, X., \& Zhang, M. (2015). Fluorescent carbon nanoparticles for the fluorescent detection of metal ions. Biosensors \& Bioelectronics, 63, 61-71. http://dx.doi. org/10.1016/j.bios.2014.07.018. PMid:25058940.

Hu, Q., Pan, Y., Gong, X., Rao, S., Xiao, L., Liu, L., \& Yang, Z. (2020). A sensitivity enhanced fluorescence method for the detection of ferrocyanide ions in foodstuffs using carbon nanoparticles as sensing agents. Food Chemistry, 308, 125590. http://dx.doi.org/10.1016/j. foodchem.2019.125590. PMid:31644970.

Khazimov, K. M., Niyazbayev, A. K., Shekerbekova, Z. S., Urymbayeva, A. A., Mukanova, G. A., Bazarbayeva, T. A., et al.(2021). A novel method and device for plastic mulch retriever. Journal of Water and Land Development. http://dx.doi.org/10.24425/jwld.2021.137100.

Kipriyanov, F. A., Savinykh, P. A., Isupov, A. Y., Plotnikova, Y. A., Medvedeva, N. A., \& Belozerova, S. V. (2021). Prospects for the use of microwave energy in grain crop seeding. Journal of Water and Land Development. h http://dx.doi.org/10.24425/jwld.2021.137098.

Li, D., Na, X., Wang, H., Xie, Y., Cong, S., Song, Y., Xu, X., Zhu, B.-W., \& Tan, M. (2018). Fluorescent carbon dots derived from Maillard reaction products: Their properties, biodistribution, cytotoxicity, and antioxidant activity. Journal of Agricultural and Food Chemistry, 66(6), 1569-1575. http://dx.doi.org/10.1021/acs.jafc.7b05643. PMid:29360356.

Liang, Z., Kang, M., Payne, G. F., Wang, X., \& Sun, R. (2016). Probing energy and electron transfer mechanisms in fluorescence quenching of biomass carbon quantum dots. ACS Applied Materials \& Interfaces, 8(27), 17478-17488. http://dx.doi.org/10.1021/acsami.6b04826. PMid:27314592.

Liu, M. L., Chen, B. B., Li, C. M., \& Huang, C. Z. (2019). Carbon dots: Synthesis, formation mechanism, fluorescence origin and sensing applications. Green Chemistry, 21(3), 449-471. http://dx.doi. org/10.1039/C8GC02736F.

Lu, W., Jiao, Y., Gao, Y., Qiao, J., Mozneb, M., Shuang, S., Dong, C., \& Li, C. (2018). Bright yellow fluorescent carbon dots as a multifunctional sensing platform for the label-free detection of fluoroquinolones and histidine. ACS Applied Materials \& Interfaces, 10(49), 4291542924. http://dx.doi.org/10.1021/acsami.8b16710. PMid:30412373.

Luo, X., Zhang, W., Han, Y., Chen, X., Zhu, L., Tang, W., Wang, J., Yue, T., \& Li, Z. (2018). N, S co-doped carbon dots based fluorescent "on-off-on" sensor for determination of ascorbic acid in common fruits. Food Chemistry, 258, 214-221. http://dx.doi.org/10.1016/j. foodchem.2018.03.032. PMid:29655725.

Miao, Y., Zhang, Z., Gong, Y., \& Yan, G. (2014). Phosphorescent quantum dots/doxorubicin nanohybrids based on photoinduced electron transfer for detection of DNA. Biosensors \& Bioelectronics, 59, 300306. http://dx.doi.org/10.1016/j.bios.2014.03.076. PMid:24747205.

Pacquiao, M. R., de Luna, M. D. G., Thongsai, N., Kladsomboon, S., \& Paoprasert, P. (2018). Highly fluorescent carbon dots from enokitake mushroom as multi-faceted optical nanomaterials for $\mathrm{Cr} 6+$ and VOC detection and imaging applications. Applied Surface Science, 453, 192-203. http://dx.doi.org/10.1016/j.apsusc.2018.04.199.

Pan, M., Yin, Z., Liu, K., Du, X., Liu, H., \& Wang, S. (2019). Carbonbased nanomaterials in sensors for food safety. Nanomaterials (Basel, Switzerland), 9(9), 1330. http://dx.doi.org/10.3390/nano9091330. PMid:31533228. 
Pandey, H., Khare, P., Singh, S., \& Singh, S. P. (2020). Carbon nanomaterials integrated molecularly imprinted polymers for biological sample analysis: A critical review. Materials Chemistry and Physics, 239, 121966. http://dx.doi.org/10.1016/j.matchemphys.2019.121966.

Parra, J. B., Silva, K. C., Valezin, P. A., Martins, R. G., Gomes, R. R., Pereira, R. S., de Melo, F. M., Morandim-Giannetti, A. de A., dos Santos, R. G., \& Panzarini, L. C. G. (2020). Preparation of Fluorescent Carbon-Based Dots from Waste Tire Pyrolysis. Journal of the Brazilian Chemical Society, 31(11), 2224-2231.

Rawtani, D., Tharmavaram, M., Pandey, G., \& Hussain, C. M. (2019). Functionalized nanomaterial for forensic sample analysis. Trends in Analytical Chemistry, 120, 115661. http://dx.doi.org/10.1016/j. trac.2019.115661.

Robby, A. I., Kim, S. G., Lee, U. H., In, I., Lee, G., \& Park, S. Y. (2021). Wireless electrochemical and luminescent detection of bacteria based on surface-coated CsWO3-immobilized fluorescent carbon dots with photothermal ablation of bacteria. Chemical Engineering Journal, 403, 126351. http://dx.doi.org/10.1016/j.cej.2020.126351.

Schneider, E. M., Bärtsch, A., Stark, W. J., \& Grass, R. N. (2019). Safe one-pot synthesis of fluorescent carbon quantum dots from lemon juice for a hands-on experience of nanotechnology. Journal of Chemical Education, 96(3), 540-545. http://dx.doi.org/10.1021/ acs.jchemed.8b00114.

Shetta, A., Kegere, J., \& Mamdouh, W. (2019). Comparative study of encapsulated peppermint and green tea essential oils in chitosan nanoparticles: Encapsulation, thermal stability, in-vitro release, antioxidant and antibacterial activities. International Journal of Biological Macromolecules, 126, 731-742. http://dx.doi.org/10.1016/j. ijbiomac.2018.12.161. PMid:30593811.

Shi, X., Wei, W., Fu, Z., Gao, W., Zhang, C., Zhao, Q., Deng, F., \& Lu, X. (2019). Review on carbon dots in food safety applications. Talanta, 194, 809-821. http://dx.doi.org/10.1016/j.talanta.2018.11.005. PMid:30609610.

Surendran, P., Lakshmanan, A., Priya, S. S., Geetha, P., Rameshkumar, P., Kannan, K., Hegde, T. A., \& Vinitha, G. (2021). Fluorescent carbon quantum dots from Ananas comosus waste peels: a promising material for NLO behaviour, antibacterial, and antioxidant activities. Inorganic Chemistry Communications, 124, 108397. http://dx.doi. org/10.1016/j.inoche.2020.108397.

Verma, A., Arshad, F., Ahmad, K., Goswami, U., Samanta, S. K., Sahoo, A. K., \& Sk, M. P. (2020). Role of surface charge in enhancing antibacterial activity of fluorescent carbon dots. Nanotechnology, 31(9), 095101. http://dx.doi.org/10.1088/1361-6528/ab55b8. PMid:31703210.

Wang, J., Wu, Y., Zhou, P., Yang, W., Tao, H., Qiu, S., \& Feng, C. (2018). A novel fluorescent aptasensor for ultrasensitive and selective detection of acetamiprid pesticide based on the inner filter effect between gold nanoparticles and carbon dots. The Analyst, 143(21), 5151-5160. http://dx.doi.org/10.1039/C8AN01166D. PMid:30251997.
Wang, C., Shang, S., Zheng, X., Lei, P., Han, J., Yuan, L., Li, Z., Wang, R., Gong, W., \& Tang, J. (2019a). Fluorescent sensors based on cudoped carbon quantum dots for the detection of Rutin. Journal of the Brazilian Chemical Society, 30(5), 988-996.

Wang, H., Liu, S., Song, Y., Zhu, B.-W., \& Tan, M. (2019b). Universal existence of fluorescent carbon dots in beer and assessment of their potential toxicity. Nanotoxicology, 13(2), 160-173. http://dx.doi.org /10.1080/17435390.2018.1530394. PMid:30621551.

Wang, H., Xie, Y., Na, X., Bi, J., Liu, S., Zhang, L., \& Tan, M. (2019c). Fluorescent carbon dots in baked lamb: Formation, cytotoxicity and scavenging capability to free radicals. Food Chemistry, 286, 405-412. http://dx.doi.org/10.1016/j.foodchem.2019.02.034. PMid:30827625.

Yadav, P. K., Singh, V. K., Chandra, S., Bano, D., Kumar, V., Talat, M., \& Hasan, S. H. (2018). Green synthesis of fluorescent carbon quantum dots from azadirachta indica leaves and their peroxidase-mimetic activity for the detection of $\mathrm{H} 2 \mathrm{O} 2$ and ascorbic acid in common fresh fruits. ACS Biomaterials Science \& Engineering, 5(2), 623-632. http://dx.doi.org/10.1021/acsbiomaterials.8b01528. PMid:33405826.

Yang, C.-Z., Liu, Y.-C., Xu, C., Bai, A.-M., \& Hu, Y.-J. (2020). A sensitive fluorescent sensor based on the photoinduced electron transfer mechanism for cefixime and ctDNA. Journal of Molecular Recognition, 33(3), e2816. http://dx.doi.org/10.1002/jmr.2816. PMid:31945234.

Yuan, J., Guo, W., Yang, X., \& Wang, E. (2009). Anticancer drug- DNA interactions measured using a photoinduced electron-transfer mechanism based on luminescent quantum dots. Analytical Chemistry, 81(1), 362-368. http://dx.doi.org/10.1021/ac801533u. PMid:19117462.

Yue, X.-Y., Zhou, Z.-J., Wu, Y.-M., Li, Y., Li, J.-C., Bai, Y.-H., \& Wang, J.-L. (2020). Application progress of fluorescent carbon quantum dots in food analysis. Chinese Journal of Analytical Chemistry, 48(10), 1288-1296. http://dx.doi.org/10.1016/S1872-2040(20)60049-4.

Zhang, Q., Sun, Y., Liu, M., \& Liu, Y. (2020). Selective detection of Fe 3+ ions based on fluorescence MXene quantum dots via a mechanism integrating electron transfer and inner filter effect. Nanoscale, 12(3), 1826-1832. http://dx.doi.org/10.1039/C9NR08794J. PMid:31899466.

Zhang, Y., Zhang, Y., Yang, W., \& Bian, L. (2018). Fluorescent reversible regulation based on photoinduced electron transfer from DNA to quantum dots and intercalation binding of DNA intercalator to DNA. Talanta, 188, 7-16. http://dx.doi.org/10.1016/j.talanta.2018.05.034. PMid:30029434.

Zhao, F., Wu, J., Ying, Y., She, Y., Wang, J., \& Ping, J. (2018). Carbon nanomaterial-enabled pesticide biosensors: Design strategy, biosensing mechanism, and practical application. Trends in Analytical Chemistry, 106, 62-83. http://dx.doi.org/10.1016/j.trac.2018.06.017.

Zhao, N., Wang, Y., Hou, S., \& Zhao, L. (2020). Functionalized carbon quantum dots as fluorescent nanoprobe for determination of tetracyclines and cell imaging. Mikrochimica Acta, 187(6), 1-10. http://dx.doi.org/10.1007/s00604-020-04328-1. PMid:32462376. 